\title{
Avicultura familiar como alternativa de desenvolvimento sustentável em comunidades ribeirinhas do Amazonas
}

\author{
Poultry familiar alternative sustainable development in the Amazon river \\ communities
}

\section{Volaille connaissent un développement alternatif durable dans les communautés riveraines Amazon}

Las aves de corral familiarizado desarrollo alternativo sostenible en las comunidades del río Amazonas

\author{
Frank George Guimarães Cruz* \\ (frankgcruz@gmail.com) \\ Ewerton Oliveira das Chagas* \\ (ewertonchagas13@yahoo.com.br) \\ Thyago Raphael Pinheiro Botelho* \\ (thyagoraphael@gmail.com)
}

Recebido em 12/11/2011; revisado e aprovado em 05/04/2012; aceito em 11/08/2012

\begin{abstract}
Resumo: A avicultura familiar tem apresentado um grande potencial para estruturar o desenvolvimento local. Neste trabalho, o foco deixou de ser apenas relacionado com mais uma renda alternativa, mas atentou-se e priorizou aumentar a oferta de proteína na dieta dos caboclos amazônicos. A avicultura familiar apresenta não somente uma fonte alimentar mas também consiste em uma alternativa de geração de renda bastante eficiente para comunidades ribeirinhas da região amazônica.
\end{abstract}

Palavras-chave: Desenvolvimento rural. Alternativa econômica. Fonte alimentar.

Abstract: The family poultry has shown great potential to shape local development. In this work the focus is no longer just associated with another alternative income, but looked up and prioritized to increase the supply of protein in the diet of amazonian caboclos. The family poultry present not only a food source but also is an alternative income generating quite efficient for riverine communities of the Amazon region.

Key words: Rural development. Economical alternative. Food source.

Résumé: L'aviculture familiale a montré un grand potentiel pour façonner le développement local. Dans ce travail, l'accent n'est plus seulement associé à un autre revenu de remplacement, mais leva les yeux et la priorité d'augmenter l'apport en protéines dans l'alimentation de l'Amazonie Caboclos. L'aviculture familiale présenter non seulement une source de nourriture mais aussi une alternatives génératrices de revenus assez efficace pour les collectivités riveraines de la région amazonienne.

Mots-clés: Le développement rural. Alternative économique. Source de nourriture.

Resumen: Las aves de corral de la familia ha demostrado un gran potencial para moldear el desarrollo local. En este trabajo el enfoque ya no es sólo asociada con otra alternativa de ingresos, pero levantó la vista y prioridades para incrementar la oferta de proteína en la dieta de la Amazonía Caboclos. Las aves de corral de la familia presentan no sólo una fuente de alimento, pero también es una alternativa de ingresos generando bastante eficiente para las comunidades ribereñas de la región amazónica.

Palabras claves: Desarrollo rural. Alternativa económica. Alimentos de origen.

\section{Introdução}

Segundo Ribeiro (2004), as várzeas amazônicas têm assegurado a sobrevivência de grupos humanos, desde os primórdios de sua ocupação, que remonta a milhares de anos. Ainda hoje, os cursos d'água e suas margens continuam sendo estratégicos no surgimento de vilas e povoados na Amazônia. Carneiro (1995) e Denevan (1996) afirmam que, apesar de ser relativamente mais fértil, a várzea é um ambiente de alto risco, que apresenta desvantagens para a ocupação, como a impossibili- dade de se cultivar ao longo de todo o ano, devido às inundações periódicas.

A expressão "agricultura familiar" vem ganhando legitimidade social e científica no Brasil, passando a ser utilizada com frequência nos discursos dos movimentos sociais do meio rural, por instituições governamentais e por estudiosos das Ciências Sociais que se ocupam de análises do meio rural (SCHNEIDER, 2003). Na Amazônia, a agricultura familiar é desenvolvida dentro dos Sistemas Agroflorestais, conhecidos no universo científico como SAF's, que foram e

* Universidade Federal do Amazonas (UFAM), Manaus, AM, Brasil. 
são implantados por comunidades indígenas, caboclas e ribeirinhas. Em algumas ocasiões, há a associação com criações de animais, sendo estas um potencial intensificador do desenvolvimento sustentável, e notória tais criações nos sítios e quintais de uma parte relevante das comunidades rurais e/ ou ribeirinhas (FRAXE et al., 2007), concordando com Montagnini (1992), que afirma serem as SAF's utilizadas em associação com cultivos agrícolas ou animais, na mesma área, de maneira simultânea ou em uma sequência temporal. Galvão et al. (2005) afirmam que, na unidade familiar, a produção se apoia no equilíbrio entre o consumo e o trabalho.

O termo ribeirinho foi utilizado para designar o indivíduo que vive e subsiste fundamentalmente do rio à margem do qual habita, tendo com este uma relação de dependência nas suas necessidades básicas de alimentação, transporte, trabalho e subsistência.

Borges (2010), em revisão histórica, afirma que a criação de animais, como frangos e galinhas, foi intensificada no período de 1870 a 1930, para servir como moeda de troca por outros produtos, o que ainda hoje é feito em comunidades ribeirinhas.

A criação caipira de galinhas em comunidades ribeirinhas dentro dos SAF's não possui a intenção de competir com a avicultura industrial, mas representa um grande potencial como componente para estruturar o desenvolvimento local (FRAXE et al., 2007), além de preencher um nicho de mercado com produtos originados de um sistema alternativo de produção e com isso atender aos consumidores com uma alimentação mais natural (CRUZ, 2011).

A avicultura familiar apresenta como vantagens: a) utilização de terras fracas e desvalorizadas, na implantação da atividade; b) baixo investimento em instalações e equipamentos; c) melhoria da qualidade da dieta do produtor e sua família através do incremento proteico; d) fixação do produtor na propriedade; e) asseguramento de renda complementar ao orçamento familiar. Como desvantagens: a) necessidade de maior área para a implantação do sistema de produção; b) crescimento lento e produção de ovos das linhagens de aves inferior ao sistema industrial (convencional); c) maior exposição das aves a possíveis agentes patogênicos.
Segundo Cerdeira (1997), para as populações amazônicas, o peixe possui um aspecto muito relevante quanto a sua importância nutricional, o que se explica por sua grande acessibilidade para as classes sociais de menor poder aquisitivo, principalmente aquelas que habitam as regiões de várzea, onde, praticamente, inexiste uma pecuária efetiva e é deficiente o sistema de abastecimento pelos grandes centros comerciais. De acordo com McGrath et al. (1991), atualmente a base econômica da ocupação ribeirinha está seriamente ameaçada devido ao declínio das atividades extrativistas tradicionais e ao colapso da agricultura de várzea. O uso dos recursos naturais disponíveis está vinculado à necessidade de subsistência do grupo doméstico, que se efetiva a partir do conhecimento do sistema ambiental, da sazonalidade, do preço de mercado, da disponibilidade dos recursos, da mão de obra, e se caracteriza como atividade extrativista (NODA, 1997).

No período da cheia, para garantir a sobrevivência da família e a continuidade da sua produção, os agricultores familiares constroem pequenos jiraus para o plantio de hortaliças e plantas medicinais e também plantam espécies resistentes às cheias em seus quintais. Nesse período, os ribeirinhos reduzem suas criações de animais, o que pode ocorrer tanto em relação ao consumo quanto à venda, deixando apenas algumas matrizes para garantir a continuidade de suas criações. Esses animais ficam confinados em instalações suspensas (maromba) ou flutuantes (CASTRO, 2009).

É importante destacar que o desenvolvimento sustentável também implica equidade social, que se fundamenta no comprometimento e no respeito por direitos fundamentais como acesso aos programas de inclusão social e geração de renda (ANDRADE, 2007).

Dessa forma, a criação de pequenos animais em SAF's, quintais ou sítios representa um aspecto relevante de atividade voltada para o desenvolvimento sustentável de comunidades rurais, seja como uma fonte proteica acessível e com seguridade alimentar, quanto a sua implementação nutricional, manejo adequado e mais natural, seja como uma fonte alternativa de renda familiar, quando, então, se compreende a possibilidade e a dinâmica existente nos povos amazônicos de comercialização planejada do excedente da produção. 
O alcance da sustentabilidade do sistema depende não só da descoberta de tecnologias, mas de um amplo processo participativo que envolva mudanças socioeconômicas e fortalecimento das entidades locais (BARBOSA et al., 2000). O objetivo deste trabalho foi avaliar a implantação e implementação da avicultura familiar em comunidades rurais do Estado do Amazonas.

\section{Material e métodos}

O trabalho foi desenvolvido nos municípios de Iranduba, Manacapuru, Anamã e Caapiranga no Estado do Amazonas (Figura 1), no período de março/2010 a março/2011. Em Iranduba, foram implantadas 03 unidades demonstrativas nas comunidades Nossa Senhora de Fátima, Boa Esperança e São José II, cada uma das quais constituída de 10 comunitários que receberam 10 galinheiros (um galinheiro/comunitário). Em Manacapuru, também foram implantadas 03 unidades demonstrativas nas comunidades São José do Calado, Palestina, Monte Horebe, Vale de Benção e Bom Jardim, sendo cada unidade constituída de 10 comunitários que receberam 10 galinheiros (um galinheiro/comunitário). Em Anamã, na comunidade Vila Arixi, e Caapiranga, na comunidade Membeca, foram implantadas duas unidades demonstrativas respectivamente, cada uma constituída de 10 comunitários, que receberam 10 galinheiros (um galinheiro/comunitário). Em razão dos municípios serem muito distintos quanto a infraestrutura, participação comunitária, posto que algumas comunidades possuíam mais afinidades com a produção agrícola que outras e dificuldade de acesso, pontos estes que foram relevantes para definir a logística de execução.

Em cada comunidade selecionada, os comunitários foram capacitados com curso sobre avicultura familiar, estes escolhidos através de reuniões com os líderes comunitários, os quais, na ocasião, definiam quais os comunitários com maior interesse e aptidão para a criação de galinhas. Foi fornecido o material para construção dos galinheiros, e cada comunitário recebeu três lotes de 60 pintos, totalizando 180 pintos até o final do trabalho, tendo os comunitários recebido assistência técnica durante 12 meses. A metodologia foi calcada em princípios participativos, o que consiste da elaboração de um diagnóstico rural participativo (DRP), em que, para conhecimento da equipe de execução do trabalho, foram abordados os principais problemas existentes nas comunidades, quais os causadores desses problemas e quais as possíveis soluções, e foram aplicados questionário, entrevistas roteirizadas e diário de campo.

\section{Resultados e discussão}

Os resultados serão expressos a priori por comunidade para posteriormente se fazer uma observação mais geral visualizando a realidade de cada município, de forma que suas características individuais sejam mais facilmente abordadas.

- Município de Iranduba - Comunidade Nossa Senhora de Fátima

Os comunitários apresentam em média 47 anos de idade; 3,4 filhos por família; $80 \%$ já tinham experiência com criação de aves; renda média mensal de $\mathrm{R} \$ 805,00 ; 50 \%$ recebem incentivos do Governo Federal como Bolsa Escola e Bolsa Família.

Ao final do trabalho os comunitários possuíam $57,38 \%$ de aves vivas, sendo que $24,47 \%$ das aves foram consumidas pelas famílias dos comunitários e/ou morreram dentro da faixa de normalidade (até 6\%), e $18,15 \%$ foram comercializadas ao preço médio de $\mathrm{R} \$ 15,00$, por ave viva do sexo masculino, e $\mathrm{R} \$ 10,00$, por ave viva do sexo feminino, contribuindo para um aumento relevante da renda financeira dos comunitários.

- Município de Iranduba - Comunidade Boa Esperança

Os comunitários apresentam em média 42 anos de idade; 2,4 filhos por família; 90\% já tinham experiência com criação de aves; possuem renda mensal média de $\mathrm{R} \$ 1.411,00$, e $30 \%$ recebem incentivos do Governo Federal como Bolsa Escola, Bolsa Família etc.

No encerramento do trabalho, os comunitários possuíam $67,06 \%$ de aves vivas, das quais $15,99 \%$ foram consumidas pelas famílias dos comunitários e/ou morreram dentro da faixa de normalidade (até 6\%), e 16,94\% foram comercializadas ao preço médio de $\mathrm{R} \$$ 15,00 , por ave viva do sexo masculino, e R\$ 
10,00, por ave viva do sexo feminino, gerando assim renda aos comunitários.

Ao final do trabalho, os comunitários possuíam $73,33 \%$ de aves vivas, sendo que $17,08 \%$ das aves foram comercializadas ao preço médio de $R \$ 15,00$ por ave viva do sexo masculino e $R \$ 10,00$ por ave viva do sexo feminino, gerando assim renda aos comunitários, e 9,58\% das aves foram consumidas pelas famílias dos comunitários e/ou morreram dentro da faixa de normalidade (até 6\%).

- Município de Manacapuru - Comunidade São José do Calado

Os comunitários apresentam em média 40 anos de idade; 4,2 filhos por família; $100 \%$ já tinham experiência com criação de aves; renda média mensal de R\$ 443,70; 50\% recebem incentivos do Governo Federal como Bolsa Escola, Bolsa Família etc.

No encerramento do trabalho, os comunitários ainda possuíam $66,35 \%$ de aves vivas, sendo que $17,94 \%$ das aves foram comercializadas ao preço médio de $\mathrm{R} \$ 10,00$ por ave viva de ambos os sexos, e 15,71\% foram consumidas pelas famílias dos comunitários e/ou morreram dentro da faixa de normalidade (até 6\%).

- Município de Manacapuru - Comunidade Palestina

Os comunitários apresentam em média 42 anos de idade, 5 filhos por família, 80\% já tinham experiência com criação de aves; renda média mensal de $\mathrm{R} \$ 562,00$ e 50\% recebem incentivos do Governo Federal como Bolsa Escola, Bolsa Família etc.

Ao final do trabalho, os comunitários possuíam $83,33 \%$ de aves vivas, das quais $26,11 \%$ foram comercializadas ao preço médio de $\mathrm{R} \$ 9,50$ por ave viva de ambos os sexos, e apenas $6,39 \%$ foram consumidas pelas famílias dos comunitários.

- Município de Manacapuru - Comunidade Monte Horebe

Os comunitários apresentam em média 39 anos de idade, quatro filhos por família, $100 \%$ já tinham experiência com criação de aves, renda média mensal de $\mathrm{R} \$ 852,00$ e 50\% recebem incentivos do Governo Federal como Bolsa Escola, Bolsa Família etc.

No encerramento do trabalho, os comunitários ainda possuíam 79,63\% de aves vivas, sendo que $14,54 \%$ das aves foram consumidas pelas famílias dos comunitários e/ou morreram dentro da faixa de normalidade (até $6 \%$ ), e apenas $5,83 \%$ foram comercializadas ao preço médio de $\mathrm{R} \$ 9,00$ por ave viva de ambos os sexos.

- Município de Manacapuru - Comunidade Vale de Benção.

Os comunitários apresentam em média 39 anos de idade; 4,7 filhos por família; 100\% já tinham experiência com criação de aves; renda média mensal de $\mathrm{R} \$ 469,00$ e $60 \%$ recebem incentivos do Governo Federal como Bolsa Escola, Bolsa Família etc.

Ao final do trabalho, os comunitários possuíam $81,23 \%$ de aves vivas, das quais $14,44 \%$ foram comercializadas ao preço médio de $\mathrm{R} \$ 18,00$ por ave viva de ambos os sexos, e 2,10\% foram consumidas pelas famílias dos comunitários. É importante salientar que, dentre todas as comunidades participantes, esta foi a que conseguiu maior rentabilidade com a venda das aves, resultando em aumento significativo na renda os comunitários.

- Município de Manacapuru - Comunidade Bom Jardim

Os comunitários apresentam em média 45 anos de idade; quatro filhos por família, todos já tinham experiência com criação de aves; renda média mensal de R $\$ 714,00$ e $80 \%$ recebem incentivos do Governo Federal como Bolsa Escola, Bolsa Família etc.

Ao final os comunitários possuíam 93,17\% de aves vivas; este elevado número de aves, decorre da programação de entrega dos pintos a esta comunidade, sendo uma das últimas a receber o lote de pintos, não tendo tempo hábil para apresentar aves em idade de abate. Além disso, 6,83\% das aves foram consumidas pelos comunitários e suas famílias. É importante salientar que, por ocasião da realização do seminário, nenhuma ave tinha sido comercializada pelos comunitários, consequentemente não gerando renda até a conclusão deste trabalho.

- Município de Anamã - Comunidade Vila Arixi

Os comunitários apresentam em média 42 anos de idade; 3,9 filhos por família; $80 \%$ 
já tinham experiência com criação de aves; renda média mensal de $\mathrm{R} \$ 739,20$ e $70 \%$ recebem incentivos do Governo Federal como Bolsa Escola, Bolsa Família etc.

Ao final do trabalho, os comunitários possuíam $90,33 \%$ de aves vivas, sendo 7,57\% foram comercializadas com preços médios de $\mathrm{R} \$ 18,00$ por ave viva de ambos os sexos, e $2,10 \%$ foram consumidas pelos comunitários e/ou mortas dentro da faixa de normalidade. Este elevado número de aves existentes no final do projeto decorre do fato de que esta comunidade foi uma das últimas a receber o último lote de pintos, contribuindo para não existir um número expressivo de aves em idade de abate para serem comercializadas. É importante mencionar que, dentre todas as comunidades, esta foi a que apresentou maior rentabilidade na venda das aves, considerando o valor de venda e a otimização de custo de produção e tempo de acabamento, aumentando significativamente a renda dos comunitários.

- Município de Caapiranga - Comunidade Membeca

Os comunitários apresentam em média 41 anos de idade, 6 filhos por família, $80 \%$ já tinham experiência com criação de aves, renda média mensal de $\mathrm{R} \$ 666,00$ e $60 \%$ recebem incentivos do Governo Federal como Bolsa Escola, Bolsa Família etc.

No encerramento do trabalho, os comunitários possuíam $76,11 \%$ de aves vivas, das quais $21,00 \%$ foram comercializadas com preços variando entre $R \$ 15,00$ e $R \$ 20,00$ por ave viva de ambos os sexos, e 2,89\% foram consumidas pelos comunitários e/ou mortas dentro da faixa de normalidade.

A começar pela média de idade dos comunitários nos municípios trabalhados, entre os quais há uma variação com cerca de 2,5 anos, sendo que destes, Iranduba com a maior média de faixa etária, apresentando comunitários com 43 anos de idade aproximadamente, e a menor média encontrada foi a dos municípios de Manacapuru e Caapiranga, com idade aproximada de 41 anos. Já em relação à média de filhos por comunitário, o município de Caapiranga apresentou a maior taxa, com média de seis filhos por família, uma das possíveis explicações para tal acontecimento está no fato de esta comunidade ser caracterizada pela atividade extrativista, fato explicado por Fraxe et al. (2007), o qual afirma que as famílias atuam de forma organizada e cooperada na produção, bem como na divisão de tarefas e trabalhos voltados para a produção dos seus quintais e roçados e, dessa forma, todos os integrantes da família atuam como a principal mão de obra nos sistemas produtivos. Outro ponto que pode estar influenciando este quadro é a relação de benefícios disponibilizados pelo Governo Federal com o intuito de auxiliar as famílias que possuem filhos pequenos e/ ou em idade escolar, com programas como o Bolsa Família e Bolsa Escola, por exemplo, nos quais $60 \%$ dos entrevistados encontram-se cadastrados, como também em outros benefícios.

Foi observado que, quanto à renda média mensal, os comunitários do município de Iranduba lideram com maior renda mensal, discordando do IBGE (2003), que mostra o município de Iranduba com a maior incidência de pobreza dentre os estudados, com $63,52 \%$. Os dados obtidos por este trabalho podem ser explicados pela alta produção de verduras e legumes nas comunidades deste município, o que não acontece nos demais municípios estudados, que têm como característica predominante o extrativismo.

Observou-se também que, apesar de o município de Anamã ter se mostrado o segundo município mais pobre, é onde se recebe o maior número de incentivos do Governo Federal, o que nos faz levantar a hipótese de que muitos incentivos poderiam estar influenciando os comunitários a dependerem cada vez mais dessa renda mensal garantida, assegurada pelo Governo, deixando de lado a produção agrícola.

Apenas no município de Manacapuru, encontrou-se comunidade em que todos os entrevistados já tinham alguma experiência de criação de aves domésticas (galinhas), realidade que não foi encontrada nos demais municípios do projeto, uma das possíveis causas pode estar em função da facilidade em se adquirir frangos congelados no interior do Estado correlacionando-os com o recebimento de incentivos fiscais. Anamã é o município que, segundo nossos dados, mais recebe incentivos fiscais e que possui menor número de comunitários com experiência em criação de galinhas, mesmo assim, a diferença foi sutil. 
Quanto à atividade de manejo e atuação dos comunitários em relação ao que propunha o projeto, este foi eficaz em objetivos diferentes para cada município. Podemos afirmar que este trabalho alcançou eficientemente o objetivo de aumentar a fonte proteica na alimentação dos comunitários do município de Iranduba, e que o mesmo projeto foi muito mais eficiente quanto à geração de renda alternativa e significativa também para o município de Iranduba, ao lado o município de Manacapuru.

Contudo os municípios menos destacados, Anamã e Caapiranga, não podem ser considerados menos eficientes quanto à comercialização, posto que foram as últimas comunidades a receberem os plantéis de pintos, não havendo tempo suficiente para que todas as aves chegassem ao peso de abate; no entanto estas comunidades estavam manejando corretamente as aves e apresentavam, para o momento e em comparação com as demais, a menor redução de custos de produção, seguindo as instruções da equipe, e os melhores preços para a comercialização, e podem também ser colocadas como as comunidades com geração de renda, a partir deste projeto, mais significativa.

\section{Conclusão}

A realização deste estudo permite-nos afirmar que agora a avicultura familiar representa não somente uma fonte alimentar segura, que contribui com o aumento da ingestão de proteína na dieta dos comunitários rurais e/ou ribeirinhos, como também consiste em uma alternativa que pode sim ser utilizada como uma atividade viável com alto potencial de contribuição para o desenvolvimento econômico de regiões menos favorecidas e mais distantes dos grandes centros comerciais da região amazônica e que pode se tornar uma alternativa de geração de renda bastante eficiente para comunidades rurais e ribeirinhas dessa região, atuando de forma significativa para a realização do tão sonhado desenvolvimento sustentável de áreas menos favorecidas quanto a ações governamentais.

\section{Referências}

ANDRADE, A.L.M. Indicadores de sustentabilidade da Reserva de Desenvolvimento Sustentável do Piranha, Manacapuru, Amazonas, Brasil. Acta Amazonica, v.
37, p. 401-412, 2007. Disponível em: <http:/ /dx.doi. org/10.1590/S0044-59672007000300011>. Acesso: 11 out. 2011. doi: 10.1590/S0044-59672007000300011.

BARBOSA, F.R.A. et al. Metodologia de pesquisa e extensão em sistemas agroflorestais para comunidades de pequenos produtores rurais, Manaus, AM, 2000. In: CONGRESSO BRASILEIRO DE SISTEMAS AGROFLORESTAIS: Manejando a biodiversidade e compondo a paisagem rural, 3., 2000, Manaus, AM. Anais... Manaus, AM: Embrapa Amazônia Ocidental, 2000.

BORGES, A.C.S. Os "ribeirinhos" do pantanal norte: temporalidades, práticas rurais e cotidiano (1870-1930). Revista Mundos do Trabalho, v. 2, p. 305-335, 2010. Disponível em: <http://www.periodicos.ufsc.br/index. php/mundosdotrabalho/article/view/12494/17238>. Acesso em: 10 out 2011.

CARNEIRO, R.L. The History of Ecological Interpretations of Amazonia: Does Roosevelt Have it Right? In: SPONSEL, L.E. Indigenous People and the Future of Amazonia. An Ecological Anthropology of an Endangered World. Tucson : University of Arizona Press. 1995. p. 45-70.

CRUZ, F.G.G. Avicultura caipira na Amazônia. Manaus: Grafisa, 2011. 114p.

CERDEIRA, R.G.P. et al. Consumo de pescado e outros alimentos pela população ribeirinha do Lago Grande de Monte Alegre - PA - Brasil. Acta Amazônica, v. 27, p. 213-228, 1997.

CASTRO, A.P. Os sistemas agroflorestais como alternativa de sustentabilidade em ecossistemas de várzea no Amazonas. Acta Amazonica, n. 39, p. 279-288, 2009.

DENEVAN, W.M. A Bluff Model of Riverine Settlement in Prehistoric Amazonia. Annals of the Association of American Geographers, v. 86, n. 4, p. 654-681, 1996.

FRAXE, T.J.P. et al. Comunidades ribeirinhas amazônicas: modos de vida e uso dos recursos naturais. Manaus: EDUA, 2007. 223p.

GALVÃO, E. et al. Análise da renda e da mão-de-obra nas Unidades Agrícolas Familiares da Comunidade Nova Colônia, município de Capitão Poço, Pará. Amazonia: Ciencia e Desenvolvimento, Belém, v. 1, n. 1, 2005.

INSTITUTO BRASILEIRO DE GEOGRAFIA E ESTATÍSTICA - IBGE. Censo Demográfico 2000. Características Gerais da População. Rio de Janeiro: IBGE, 2003. 178p.

MONTAGNINI, F. Sistemas Agroflorestales: principios y aplicaciones en los trópicos. Costa Rica: San Jose, 1992. 622p.

McGRATH, D.G. et al. Varzeiros, geleiros e o manejo dos recursos naturais na várzea do Baixo Amazonas. Cadernos do NAEA, v. 11, p. 91-125, 1991.

NODA, S.N. et al. O trabalho nos sistemas de produção de agricultura familiar na várzea do estado do Amazonas. In: NODA, H.; SOUZA, L.A.G.; FONSECA, J.M. (Ed.). Duas décadas de contribuições do INPA à pesquisa agronômica no Trópico Úmido. Manaus: INPA, 1997.

RIBEIRO, R.N.S.; TOURINHO, M.M.; SANTANA, A.C. Avaliação da sustentabilidade agroambiental de unidades produtivas agroflorestais em várzeas fluvio-marinha de Cametá - Pará. Acta Amazônica, v. 34, p. 359-374, 2004. SCHNEIDER, S. A pluriatividade na agricultura familiar. Porto Alegre: UFRGS, 2003. 